\title{
Systematic Representation of Relationship Quality in Conflict and Dispute: for Construction Projects
}

\author{
Mostafa Babaeian Jelodar, Tak Wing Yiu and Suzanne Wilkinson \\ Department of Civil and Environmental, Faculty of Engineering, University of Auckland, New Zealand
}

\begin{abstract}
The construction industry needs to move towards more relational procurement procedures to reduce extensive losses of value and avoid conflicts and disputes. Despite this, the actual conceptualization and assessment of relationships during conflict and dispute incidents seem to be neglected. Via a review of literature, relationship quality is suggested as a systematic framework for construction projects. General system theory is applied and a framework consistent of four layers respectively labelled as triggering, antecedent, moderation and outcome is suggested. Two different case studies are undertaken to represent the systematic framework; which verifies that changes in contracting circumstances and built environment culture can affect the identified layers.

Through system reliability theories a fault tree is derived to represent a systematic framework of relationship quality. The combinations of components, causes, and events for two case studies are mapped out through fault tree. By analysing the fault tree the combination of events that lead to relationship deterioration may be identified. Consequently the progression of simple events into failure is formulized and probabilities allocated. Accordingly the importance and the contribution of these events to failure become accessible. The ability to have such indications about relationship quality may help increase performance as well as sustainable procurement.
\end{abstract}

Keywords: Relationship quality, conflict, dispute, fault tree analysis, general system theories.

Paper Type: Research article

\section{Introduction}

It is believed that the traditional procurement systems and implementation methods associated with construction projects are inadequate and inefficient (Egan, 1998; Latham, 1994; Wolstenholme, 2009). Collaboration has been emphasised and the focus is mainly on relational contracting, partnering and alliancing (Bygballe, Jahre and Swärd, 2010; Cox and Thompson, 1997). Supply chain management, within the domain of industrial management and business mainly focused on direct relationships (Gualandris and Kalchschmidt, 2014), whereas construction generally looked at contracting methodologies (Alderman and Ivory, 2007; Eriksson, Atkinson and Nilsson, 2009; Jelodar and Yiu, 2012a). Wolstenholme (2009) believed that most client business models in construction are focused on short-term gains; for instance suppliers who can deliver long-term sustainable solutions are not rewarded. Adding to this the

Copyright: Construction Economics and Building 2015. C 2015 Mostafa Babaeian Jelodar, Tak Wing Yiu and Suzanne Wilkinson. This is an Open Access article distributed under the terms of the Creative Commons Attribution 4.0 Unported (CC BY 4.0) License (https://creativecommons.org/licenses/by/4.0/), allowing third parties to copy and redistribute the material in any medium or format and to remix, transform, and build upon the material for any purpose, even commercially, provided the original work is properly cited and states its license.

Citation: Jelodar, M.B., Yiu, T.W. and Wilkinson, S., 2015. Systematic Representation of Relationship Quality in Conflict and Dispute: for Construction Projects, Construction Economics and Building, 15(1), 89-103. DOI: http://dx.doi.org/10.5130/ajceb.v15i1.4281

Corresponding author: Mostafa Jelodar; Email - mjel010@aucklanduni.ac.nz

Publisher: University of Technology Sydney (UTS) ePress 
high risks involved in construction and unequal risk allocations triggers a dominant blame culture among industry practitioners (CIRC, 2001; Egan, 1998). All of this indicated that there should be rigorous reflections of relational practices and attributes. However only a limited number of studies have focused on actual relational features of the parties involved in construction (Jelodar, Yiu and Wilkinson, 2013b; Meng, 2012; Yeung, Chan and Chan, 2012). On the other hand some studies have acknowledged that various events, arrangement and processes foreseen for the purpose of executing construction activities could influence relationships (Kumaraswamy et al., 2005; Ling and Li, 2012; Yeung, Chan and Chan, 2012). Conflict and dispute and their handling mechanisms, communication and reporting matrix, procurement strategy, clarity, education and training may affect relationships and its associated attributes. These relationships have generally been observed in client, contractor, sub-contractor and supplier context. Based on this vision relational attributes, strategies and processes emplaced within project scope could be systematically intertwined where relationships are concerned. However events such as conflict and dispute incidents, and their handling strategy - due to their impact on relationship quality should be extensively under scrutiny (Jelodar and Yiu, 2012b). However due to the frequent occurrence and importance of incidents such as conflicts and disputes, it is vital to understand what is the construct of a systematic framework involving conflict/dispute and relationship quality. Furthermore can relationship quality deterioration be seen as a systems failure to sustain relationships? The current study will suggests and demonstrate a systematic framework representing the interactions of conflict and dispute associated events, with the relationship quality of the parties involved; in addition system reliability theories are applied to model failure and relationship deterioration within the systematic framework.

\section{Relational Approaches in Construction}

In modern construction project procurement the goal is inspiring clients, consultants, contractors and suppliers to work together towards improving quality, lowering costs, dispute mitigation, innovation, and sharing risks. The challenge is to overcome the project focused perception in the industry and advocate a more valuable relationship-based model (Love et al., 2002). There is a need for change, as mentioned in many construction industry reports (Egan, 1998; Wolstenholme, 2009). There is a consensus that the current code of conduct and traditional procurement strategies in the construction industry are to a large extent responsible for the existing fragmentation and deficiencies (Love et al., 2002). However the industry has tried to make changes. Collaboration and communication has been advocated and early involvement of experts and project participants in the form of applying constructability concepts has been suggested (Jelodar, Yiu and Winlkinson, 2013a). Contracting methodologies have undergone major revisions and changes. In fact contracts such as commitment to fair construction contract charter, the engineering and construction contracts and also the new engineering contract have all tried to incorporate collaboration with a more relational vision in construction (Cox and Thompson, 1997). Apart from this the increase in construction industrialisation is driving changes to business models and practitioners are realizing the value of long-term relationships (Bygballe, Jahre and Swärd, 2010). There are many studies which aimed to advocate partnering, alliancing or other joint ventures as a mean of improving relationships in construction (Ling et al., 2014; Meng, 2012; Yeung, Chan and Chan, 2012). However despite this appreciation of advantages there still exists major underperformance in implementing relational strategies (Winch, 2000).

Although relationships status is considered a key factor in developing and streamlining construction projects, there are major differences in how they are formed or enforced (Jelodar and Yiu, 2012a; Yeung, Chan and Chan, 2012; Zou et al., 2014). Some believe it is a gradual and organic development of trust, and commitment between parties which only endures over a 
significant period of time (Bygballe, Jahre and Swärd, 2010). However on the other hand there is a vision that relationships could be engineered in contractual and working arrangements. These two different perspectives, plus the difficult nature of relationships in construction projects, have produced a lot of confusion as to what elements may define or influence relationships. However agreed constructs for defining and evaluating relationships exists in marketing and business research. In these knowledge areas customer retention is important, thus the concept of relationship quality was introduced to provide an indication of relationship status between buyer and seller (Crosby, Evans and Cowles, 1990). This has also been expanded to the relationships in the supply chain (Lages, Lages and Lages, 2005). Relationship quality is defined by HennigThurau and Klee (1997) as the "degree of appropriateness of a relationship to fulfil the end needs of a customer", but attributes have also been identified and Crosby, Evans and Cowles (1990) stated there is a consensus that relationship quality is a high-order construct of attributes such as trust, satisfaction and commitment.

As mentioned the movement of relationship preservation and sustainable procurement within the construction industry has similarly started (Pheng, 1999). Consequently understanding relationships and their associated quality in different projects is essential. Parties with the ability to assess and monitor relationships will have better ability to plan, take pre-emptive or if necessary corrective actions in their relationships. In addition, with the information on relationship quality in hand, parties can also plan their actions based on their relational preferences. The basic idea is to observe the right quality of relationship and assign it to the right circumstance. Recently the concept of relationship quality has been proposed in construction (Jelodar and Yiu, 2012b; Jelodar, Yiu and Wilkinson, 2013b).

In this study, relationship quality is associated with major attributes, strategies and actions that may be systematically interconnected with each other. It is known that conflict and dispute incidents are very common in construction and some even believe that they are inevitable; threatening the long-term relationship of project participants (Barnett, 1997; Cheung and Yiu, 2006). Conflicts and disputes are triggered and manifested through a succession of events, and dealt with through certain handling strategies; all of which will most probably have implications on relationships. Hence a systematic framework which demonstrates the interrelation between conflict, dispute, and relationship quality in construction projects could be envisioned.

\section{Relationship Quality in Conflict and Dispute Incidents}

Different models and structures have been suggested to conceptualize relationship quality making it applicable to different types of business relationships, however as indicated by Crosby, Evans and Cowles (1990) the general consensus regards relationship quality as a high order construct with antecedents and outcomes. In line with this, four different variable layers of triggering, antecedent, moderation and the outcome, plus a constant layer of relationship quality determinants has been proposed in construction projects (Jelodar and Yiu, 2012b). Basic events initiating changes in relationship quality specify the triggering layer which can influence both the antecedent layer and relationship quality. For instance, conflict and dispute causes could be included in the triggering layer since they affect relationships; even their handling and resolution styles most probably will affect the relationships (Gardiner and Simmons, 1992). The antecedent layer is a complex layer containing conflict represented by Pondy's (1967) process model and ultimately dispute as illustrated in Figure 1. They are seen as important antecedents which mainly negatively influence relationship quality in construction Chaudhuri $(1997,1998)$.

Ignoring or delaying the resolution of conflicts can have serious implications for present and future relationships of the parties involved in construction activities and projects (Bristow and Vasilopoulos, 1995). However components of the conflict process model; as part of the 
antecedent layer, can positively or negatively influence relationship quality. The framework in Figure 1 is all about the systematic influence of conflict/dispute events on relationship quality; hence the next layer of influence for relationship quality is the moderation layer which includes conflicts and disputes management strategies (Figure 1). Contrary to the previous layers the final layer is the outcome layer and is influenced by the relationship quality.

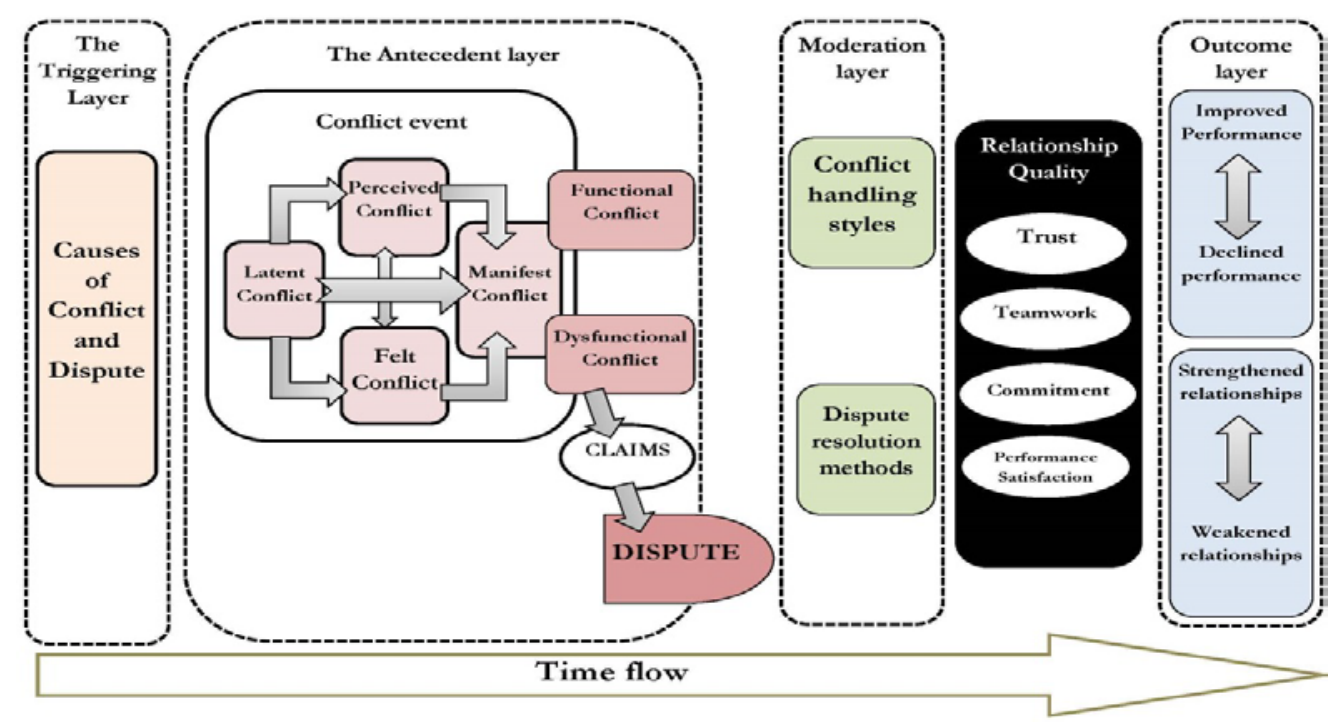

Figure 1: The general systematic framework of relationship quality for construction

In this approach the bench mark relationship quality is dependent on variations of associated attributes. These attributes are included in the relationship quality (constant) layer of the framework (Figure 1). Having conducted a thorough literature search, trust has emerged as the most important relational attribute or component in construction (Ling et al., 2014; Meng, 2010; Yeung, Chan and Chan, 2012). Trust is profoundly positive on relationship quality and it can also control opportunistic tendencies of different parties leading to a healthier relationship (Cox and Thompson, 1997). It is believed that collaboration coexists with communication under the umbrella of teamwork as another indicator of relationship quality. Che Ibrahim, Costello and Wilkinson (2013) have advised that apart from leadership; trust, respect, and a single team focus; collective understanding; commitment from project alliance board; creation of single and colocated alliance team; and free flow communication were also means of achieving team integration. Without effective teamwork there will be deficiencies in joint understanding and planning, which could compromise the relationship (Chen and Chen, 2007). Commitment through top management and leadership should be injected and provoked in relationships (Bennett, Peace and CIOB, 2006; Ling et al., 2014). Lack of commitment will reduce quality and organizations will suffer, which could also be disastrous to relationships (Rahman and Kumaraswamy, 2004). Satisfaction has always been associated with customer retention in the business environment (Crosby, Evans and Cowles, 1990; Hennig-Thurau and Klee, 1997); however in construction, parties should be satisfied with a series of elements which resemble performance. In fact (Yeung et al., 2007) have indicated that success in relational approaches such as partnering is heavily dependent on satisfaction with time and cost performance and top management commitment.

In addition some strategies and actions were also described to maintain and facilitate these main attributes, resulting in better relationship quality; these strategies are sometimes confused with the original attributes of relationship quality. For instance sharing information and resources, fair risk allocation, win-win attitude, integrity, respectful behaviour, training, leadership support to 
incentivising the parties into collaboration, are all examples of such strategies (Bygballe, Jahre and Swärd, 2010; Ling and Li, 2012; Ling et al., 2014; Meng, 2010; Yeung, Chan and Chan, 2012).

\section{Methodology}

In order to demonstrate a systematic view of relationship quality the earlier framework presented by Jelodar and Yiu (2012b) is modified and disseminated as a proposed system for relationship quality. This generic system model for relationship quality in construction activities is justified via general systems theory, which could be employed as a communication and translation mechanism for different areas of science and engineering (Blanchard and Fabrycky, 2011). The outcome system model is demonstrated via two case studies in the construction project conflict, dispute and contract arrangement settings. The cases are selected with different contractual arrangements to demonstrate the potential systematic change in the proposed generic model. For each of the cases a system framework is derived. This system framework is the basis for applying system analysis tools such as system reliability analysis, and ultimately a fault tree is developed to demonstrate the possible failure models of the two potential system frameworks. The Fault Tree Analysis (FTA) provides an indication of possible causes that may result in relationship failure in different working and contractual environments.

\section{Model Conception: Systematic Approach to Relationship Quality}

The framework of Jelodar and Yiu (2012b) demonstrates that a chain of events can influence relationship quality in construction projects. The focal point however is to identify a model that represents relationship quality in the best possible manner. In this framework the events of the first three layers will simultaneously affect each other in addition to the relationship quality and outcome layer; influencing attributes such as trust, teamwork, commitment and performance satisfaction. This forms the basic idea that a systematic concept may be suitable for this structure. The system mind set has different perspectives and interpretation. Systems have been defined as an organized complex or unitary whole formed by the assemblage or combination of things or parts (Kast and Rosenzweig, 1970). It has also been regarded as functionally related parts forming a unitary whole with the emphasis on functional relationships, not just any procedure (Blanchard and Fabrycky, 2011). Hitchins (2007) believed that systems possess some degree of order and that a discernible pattern or configuration exists. What is generally observed is that in systems generic theories; relationships, dependencies or interdependencies transpire among different components in order to serve a purpose.

Systems are identified with their components, attributes and relationships. Components are the basic parts of a system, attributes are the properties of each components and the system as a whole, and finally relationships are the links between pairs of components, in order for the pair to operate as part of the whole and contributing to the system purpose. State is the situation of the system in a certain point of time which may vary during a period of time, and is highly dependent on system attributes and relationships. The observed changes of system state within a time frame exhibits system behaviour, and a set of system behaviours with their corresponding timing and sequence will create a process. It is vital to highlight that a process engaging one component may influence the process of another component (Blanchard and Fabrycky, 2011). The basic implication of this is that different concepts can be represented through a system or subsystems within broader systems (Blanchard and Fabrycky, 2011). In conceptual systems, symbols represent the attributes of components, ideas plans, concepts and hypothesis. 


\section{Model Conception: Emergence of Relationship Quality as a System}

The key question is whether relationship quality exhibits any compatibility with the systematic preview mentioned in the previous section. The first step is to identify the possible components of relationship quality. This means including the boundaries and constraints which may determine the components and the potential links of the model, and conceptualizing the most appropriately fitted behaviours and processes for the system. In construction activities when a professional setting for collaboration is created such as a project charter, the potential parties begin to know each other even before initiation of actual work and a framework for relationships is formed. This framework is born and shaped through the local working environment, legal setting, and working culture of the project participants. The working culture will range from actual practices, procedures, and behavioural trends of the practitioners. Other constraints of the relationship framework are contract provision governing project work, and uncertainties of the project. When ultimately a contract is conceived the stage is set for a professional relationship. Furthermore contracts can define basics of working relationships (Sako, 1992). This relationship framework can be formalized into a conceptual system as demonstrated in Figure 2, which is a progression of the Jelodar and Yiu (2012b) framework into a system overview for relationship quality.

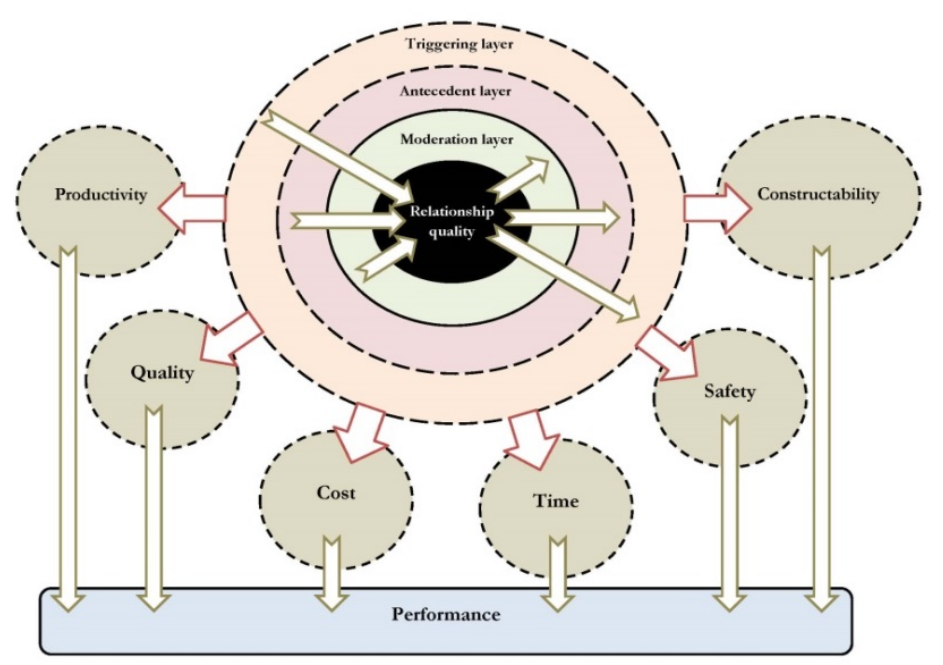

Figure 2: The relationship quality system overview

The system illustrated in Figure 2, clearly demonstrates the four main interactive layers of relationship quality framework. This framework also demonstrates the subsystems or other components in correspondence with the core system. For the working and collaborative environment provided by the construction projects, a sequence of events which are process, contract and behaviour related encompassed by uncertainty, may lead to conception of issues imposing relationship changes. These issues can commonly trigger possible conflicts and dispute, and at the same time affect the manifestation of the conflicts in the antecedent layer (Figure 1). Ultimately it can determine the type of conflict/dispute resolution approach foreseen in most contractual agreements at the moderation layer. This chain of events, as illustrated by the arrows moving towards the inner layers of Figure 2, determines the state of relationship quality at the core of the system. On the other hand events from the inner layers will also influence change to the other layers, as demonstrated by the outward arrows in Figure 2. For instance the deterioration state of relationship quality can trigger other misunderstandings and issues which ultimately can have more implications on relationships. The deterioration or improvement of relationship quality may also change the settings of actions and behaviour for better or for worse, thus influencing the components conforming to the antecedent and moderation layer as part of a 
systematic loop. This interpretation is more or less in line with Blanchard and Fabrycky (2011) systems definition mentioned previously and demonstrates that: 1) the properties and behaviours of each component in the set will affect the properties and components of the set as a whole; 2) the properties and behaviours of each component of the set depend on the properties and behaviour of at least one other component in the set; 3) each possible subset of components meets the two requirements listed above and the components cannot be divided into independent subsets.

Systems are also classified into static and dynamic. In static systems, although there are structural components involved, in the absence of operating components, the state does not change. Unlike other physical or conceptual man-made industrial, construction and service providing systems, the relationship quality system does not have retirement or phase-out, and positive or negative implications of relationships exist in a static mode. The level of interaction may vary but once the two parties are acquainted and begin work their relationship will begin to form and a quality could be associated with it. In addition a perceived and potential relationship quality exists all the time, even when the parties are not interacting. The perceived relationship quality is relevant to experience and could potentially play as a driver or deterrent in future working relationships. Based on this perception, relationships could even evolve during the static periods. During this period the influential factor on perception, and ultimately the relationship quality, will primarily be the party's reputation because there are no direct interactions. Instead, a dynamic system will display behaviour because the change of state takes place through a combination of structural components, with operating or flow components. A static system normally serves as a useful component for a dynamic system. Therefore when interaction begins between the parties then the static mode of the relationship quality system changes and becomes dynamic. This is manifested through the interaction of its four main layers ultimately imposing different behavioural changes hence the system is dynamic during project interactions. As illustrated in Figure 2, the internal layers are born within the external layers but once the layers are born it does not mean that the previous layer dissolves or perishes. For instance when the antecedent layer and moderation layer are functioning during conflict manifestation and management, other triggers of conflict can initiate new conflicts or escalate the situation and directly change system state and behaviour; according to Jehn and Mannix (2001) conflicts have a dynamic nature.

\section{Model Conception: Relationship Quality Synthesis}

General systems theory is the advocate of interdisciplinary amalgamation or synthesis in favour of a greater whole which is the encircling system (Hitchins, 2007). Synthesis could be regarded as a communication and translation mechanism for different areas of science and engineering. Therefore the interactions of a system with other concepts are of great importance. For instance there is evidence that relationships can affect issues such as level of collaboration and communication (Meng, 2010). In Figure 2 the core system of relationship quality is shown to have implications on indicators such as productivity, quality, cost, time, safety and also constructability. Relationship variations may influence many factors; however the abovementioned factors are of significance since they more or less define the overall performance of the project in question (Chan and Chan, 2004).

\section{Representing Relationship Quality Systems through Case Studies}

The elaborated systematic framework suggests that unique models can be drawn for relationship quality in different construction projects. The events of the first three layers associated with the system are variable, and are a function of the project conditions; whereas the relationship quality 
layer is constant throughout different projects and comprises of relational attributes discussed earlier. In this section two cases are used to illustrate the different compositions of the relationship quality; summary of the cases are included in Table 1.

Case one: Although any potential cause can trigger conflict or dispute, some causes may be more probable. For instance in the case of the highway project, part of government's and the client organization's responsibility is to free all the lands for the road and also control existing traffic. If the client or the government fails to do so, this may result in late availability of the site and limitations in access, which are project uncertainty related causes. Other causes may be due to rigid time constraints of the FIDIC contract associated with this particular case, thus disputes may arise that are more contract and process related, or even poor communication could trigger conflict because the contract is fragmented into design-bid-built procedures. Thus some causes are more probable than others, as illustrated in the multi-layered system of case one (Figure 3).

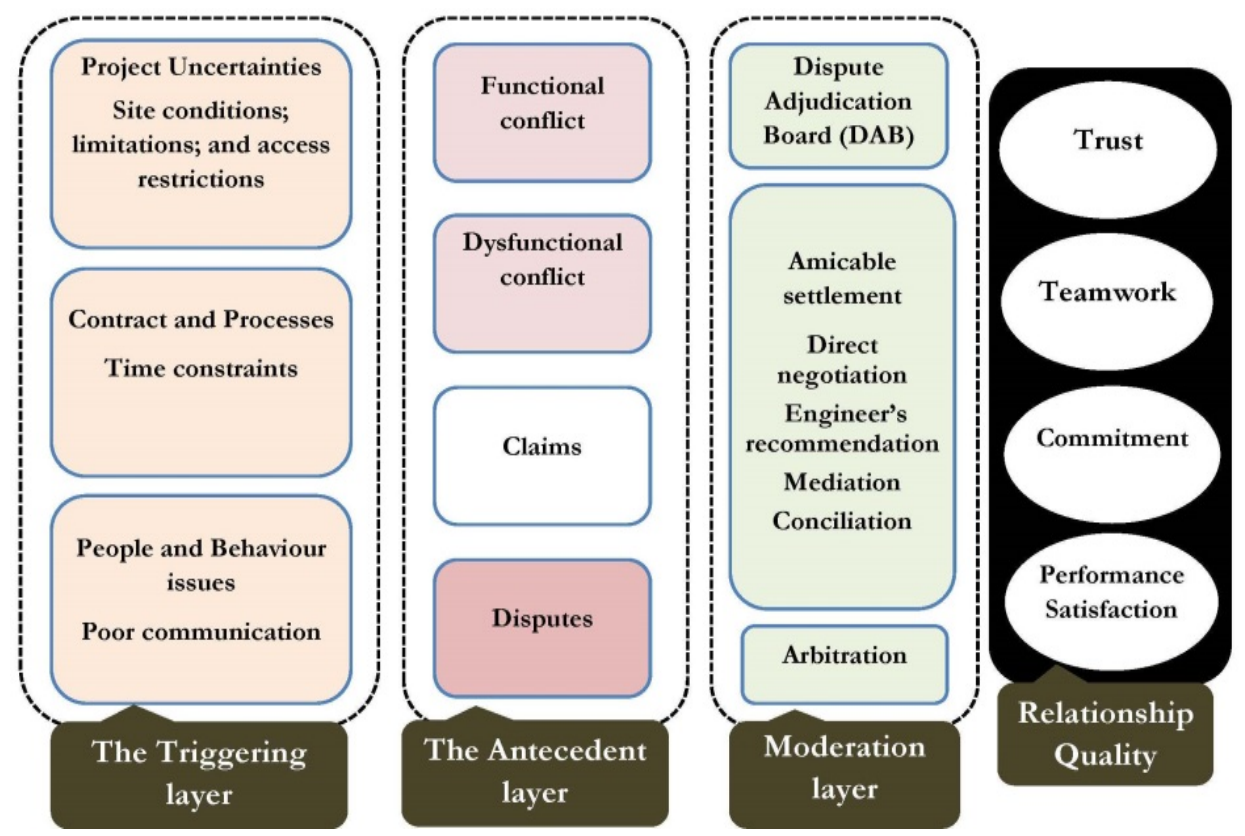

Figure 3: Systematic framework for case one

For the antecedent layer the occurrence of both functional and dysfunctional conflicts, are probable, as are claims and disputes. But as far as the moderation layer is concerned, the contract has previously defined means of conflict management and dispute resolution. The events of this layer range from Dispute Adjudication Board (DAB) to amicable settlement or arbitration. However amicable settlement itself may be obtained through a variety of different methods (direct negotiation, the engineers recommendation, mediation and conciliation) (Totterdill, 2006); which may diversely affect relationship quality. The events in the layers may or may not occur; or several loops of the events may occur each time, triggering different conflicts or disputes. Causes may trigger other conflict and dispute events at the same time or at different times, in line with the discussion in the model conception.

Case two: Although like the previous case any cause of conflict and dispute may occur, some causes are more likely to occur according to the nature of project; such as technical problems due to complexity of design and construction, design errors, ambiguities, change orders, and lack of experience with the type of work performed. For the antecedent layer functional, dysfunctional conflicts and disputes may occur. The contract conditions determine the dispute resolution process in four general steps, which is completely different with the conditions mentioned in the previous case (Table 1). A similar systematic illustration is drawn for this case and is quite different compared to the first case (Figure 4). The systematic approach allows the 
practitioners to draw their unique system based on the events that are most likely to happen in the related project. The framework provides a mean of evaluation for relationship quality at each step of the project, since most of the influential events are indicated in the corresponding layers.

Table 1: Case study description

\begin{tabular}{|c|c|c|}
\hline & Case one & Case two \\
\hline Project type & Infrastructure- Ring Road Project & Commercial-Multi story \\
\hline Description & $\begin{array}{l}\text { Upgrading of } 33.4 \mathrm{~km} \text { of highway } \\
14.2 \mathrm{~km} \text { of bituminous asphalt concrete surfacing } \\
19.2 \mathrm{~km} \text { of new road } \\
41 \text { new structures, } 6 \text { flyover bridges, } 23 \\
\text { pedestrian bridges, and } 12 \text { culverts. }\end{array}$ & $\begin{array}{l}\text { Constructed of a pre-cast concrete structure } \\
\text { with a substantial concrete shear core at the } \\
\text { centre, } 15 \text {-level, and } 12 \text { levels of office space } \\
\text { Contemporary architectural design } \\
\text { NZ Green Building }\end{array}$ \\
\hline $\begin{array}{l}\text { Procurement } \\
\text { strategy }\end{array}$ & Design-bid-built & Design-Built \\
\hline $\begin{array}{l}\text { Contract } \\
\text { Condition }\end{array}$ & FIDIC conditions of contract (red book). & New Zealand Standard form NZS 3910:2003 \\
\hline $\begin{array}{l}\text { Dispute } \\
\text { resolution } \\
\text { process }\end{array}$ & $\begin{array}{l}\text { Starts with Dispute Adjudication Board (DAB) } \\
\text { then amicable settlement and the last resort is } \\
\text { arbitration. }\end{array}$ & $\begin{array}{l}\text { The proposed dispute resolution procedure of } \\
\text { this contract starts with engineer review, then } \\
\text { mediation if not settled, through dispute } \\
\text { tribunal or arbitration. }\end{array}$ \\
\hline Project Size & $\begin{array}{l}\text { US } \$ 67.25 \text { million in the main contract for the } \\
\text { road construction and US } \$ 18.77 \text { million In a } \\
\text { supplemental contract. }\end{array}$ & NZD\$120 million \\
\hline
\end{tabular}

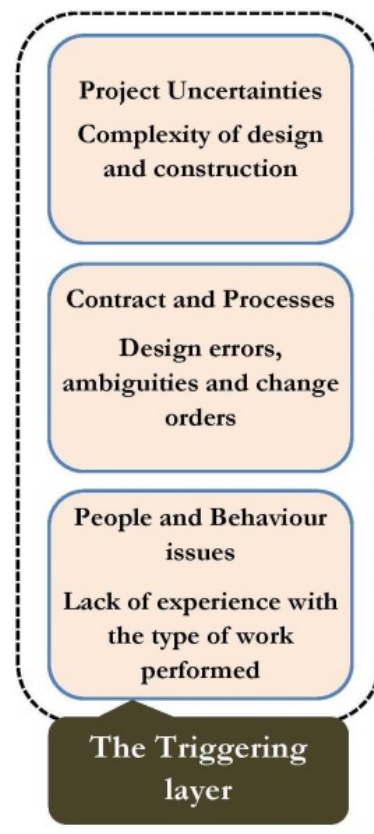

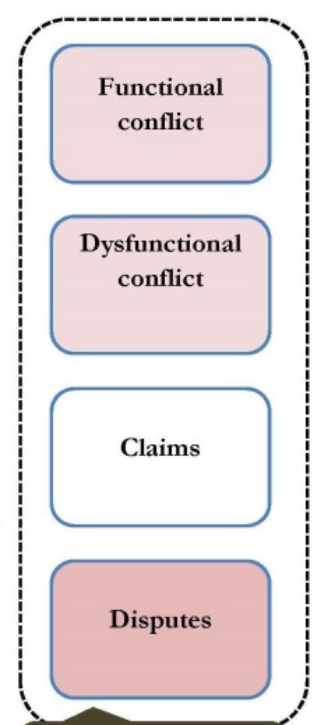

The Antecedent layer

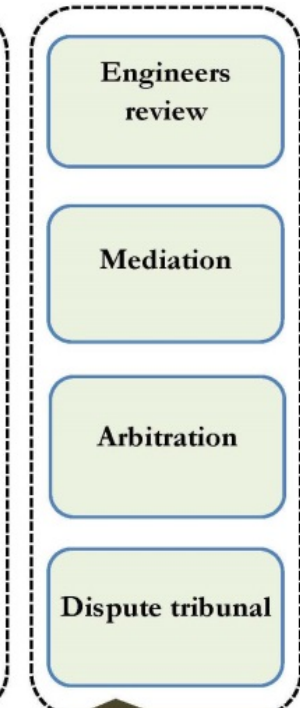

Moderation layer

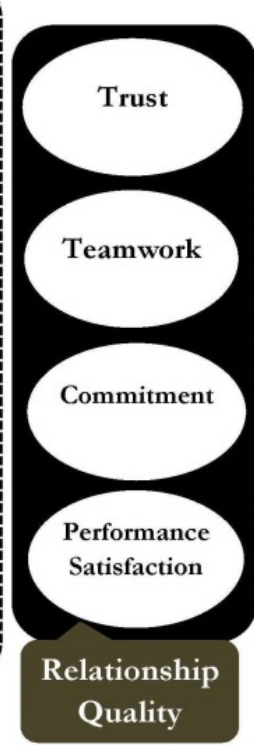

Figure 4: Systematic framework for case two

\section{The Application of System Reliability Analysis}

Functions, tools and techniques available in general systems theory could also be applied for better assessment and arrangement of the system framework. For relationships, deterioration or failure can be regarded as an undesired outcome. Accordingly, through the use of system reliability analysis, root causes of relationship deterioration could be identified and assessed. 
Concepts such as quality, availability, safety, security, and dependability are closely and deeply associated with systems reliability (Høyland and Rausand, 2009). Quality is regarded as conformance to specification in satisfying needs and reliability is the ability to continue this conformance via the developed system. Reliability could be seen as an extension of quality into a time domain. The best phases for reliability engineering are the conceptual and design phase of the system. Valid and reliable assessment of reliability will lead the way for better engineering of the system thus enhancing quality and operations (Hitchins, 2007).

The causal nature of risks analysis is predominantly accomplished by reliability techniques such as Failure Mode and Effect Analysis (FMEA)and Fault Tree Analysis (FTA). Høyland and Rausand (2009) defined the fault tree as "a logic diagram that displays the interrelationships between a potential critical event (accident) in a system and the possible reasons for this event". FTA is suitable for analysing the relationship quality system because it allows the consideration of environmental conditions, human errors, normal events and also specific component failures. The fault tree can be either qualitative or quantitative and normally aims to list the possible combinations of factors, errors, events, and component failures that may result in a critical event in the system. The Fault Tree Analysis (FTA) also helps to identify the probability of occurrence associated with a critical event during a specified time interval.

\section{System Failure Models for Case Studies}

After analysing the two cases it was established that the system framework for each case is a dynamic system, which is influenced by a number of layers and their incorporated events, specific to the condition of each case. The failure of relationship quality system is defined as the failure of system components situated in the assigned layers of the system in balancing each other out, in favour of a retained beneficial relationship to all sides. Conflict management and dispute resolution strategies in the moderation layer are functioning to balance, prohibit, or moderate possible conflicts and disputes emerging in the antecedent layer, which is in succession to initial events in the triggering layer.

System failure models such as Fault Tree Analysis (FTA) try to encapsulate and evaluate the possible failure of the system according to the components derived, for each project discussed. FTA graphically associates and links the simple system components (basic events) to the system state or failure which is the top event. This graphical illustration is justified by logical symbolism called gates. In drawing the fault tree the top event is normally the system failure notion. Accordingly for this framework the top event would be deterioration of relationship quality. The Fault Tree for both of the previous cases is driven based on their unique system frameworks. Figure 5 shows the Fault Trees related to the mentioned cases. On the left side the sequence of events related to the triggering and antecedent layer with its association to relationship quality, is logically mapped out. As a result, the simple triggers that may affect relationship quality are linked to the top event. This side remains the same for both cases despite the fact that the probabilities of occurrence for these basic events are different in the two cases. The right side however is associated with the moderation layer, and due to differences in contract type and dispute resolution procedures of each case, the Fault Tree logical mapping is completely different. This difference is clearly exemplified in Figure 5 by encircling the dispute resolution procedures related to the moderation layer of each case. The logical gates and standards used in the FTA model are also shown in Figure 5.

\section{Discussion}

Initially the generic system model was suggested and the adapted models were formulated for different cases and construction relationships according to their cultural, legal and contractual 
conditions. The logical setting and association of the FTA starts primarily with the fact that, for any relationship to deteriorate, an adversarial event is required that has the potential to turn into a conflict or dispute incident. In addition the problem must go unresolved. These events are linked and demonstrated in Figure 5, via an "and" gate to the top event. Figure 5 also shows that conflicts either directly arise from causes or from contract provisions and processes. In addition, disputes are linked with conflicts or unaccepted claims. Causes in this section are also split into two new branches; project uncertainty related and people and behaviour related. Each of these branches is associated with simple events which have been previously identified as common sources of conflict and dispute (Jelodar and Yiu, 2012a). The conditions of contract will dictate how an adversarial event should be resolved. As demonstrated in Figure 5, the two cases have totally different conflict management and dispute resolution strategies.

In Case 1 the focus is basically on more informal and more effective dispute resolution methods whereas in Case 2, mediation is mentioned but ultimately the dispute tribunal may get involved, which can be devastating for relationships. Another issue with the Fault Tree model in Figure 5 is that some events, especially causes of conflict and dispute, are more likely to occur in different conditions. As discussed for case one, the late availability of the site, access limitations, time constraints, and poor communication, are more likely to occur based on the nature the project. Accordingly the FTA model can illustrates the possible combination of causes and events that may lead to relationship deterioration in construction projects. Furthermore, if the probabilities associated with each event of the Fault Tree are obtained, the ultimate probability of system failure, in this case relationship quality deterioration could be obtained. The probability of the top event can be determined using probabilistic and mathematical tools within the Fault Tree framework. With reference to the FTA performed and illustrated in Figure 5, the general relationship of the top event with its consecutive events can be formalized as follows (where $\mathrm{X}$ represents the occurrence on the certain event):

Equation 1:

$$
T_{\text {top event }}=X_{\text {Disput Adverserial }}^{\text {Events }} \underset{\substack{X_{\text {Unresolved }} \\ \text { Problems }}}{\cap}
$$

Where:

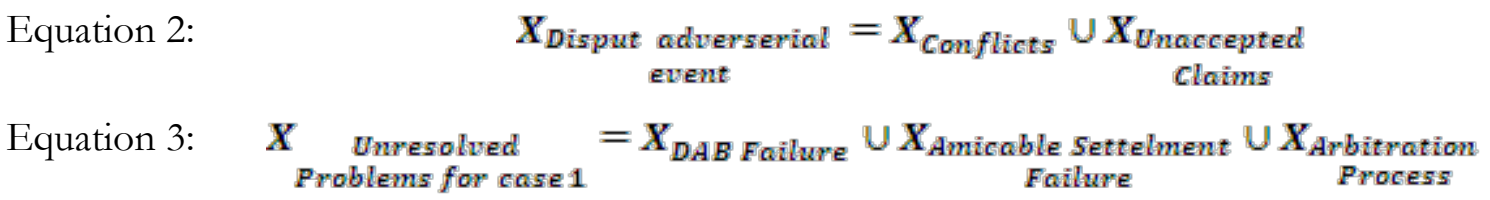

Equation 4:

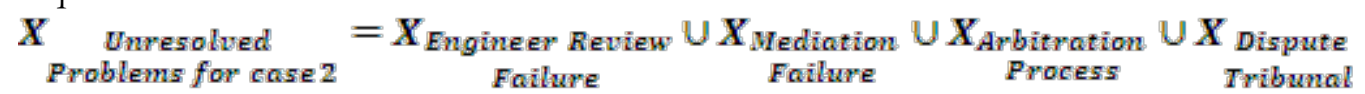

The consecutive events of the FTA model (Figure 5) are associated with the top event using the logical gates representing Union (And Gate) where $A \cup B=\operatorname{def}\{x I x \in A$ or $x \in B\}$ or intersection (Or Gate) where $A \cap B=\operatorname{def}\{x I x \in A$ and $x \in B\}$ as exemplified above. According to Figure 5 and the trend demonstrating the turn of events above, probabilities of each event can be acquired and allocated to the simplest events established at the bottom of the Fault Tree. In addition, by using Birnbaum's Measure of Component Importance, the weights related to each cause of relationship quality deterioration can be determined (Andrews and Beeson, 2003; Cheung and Yiu, 2006). 


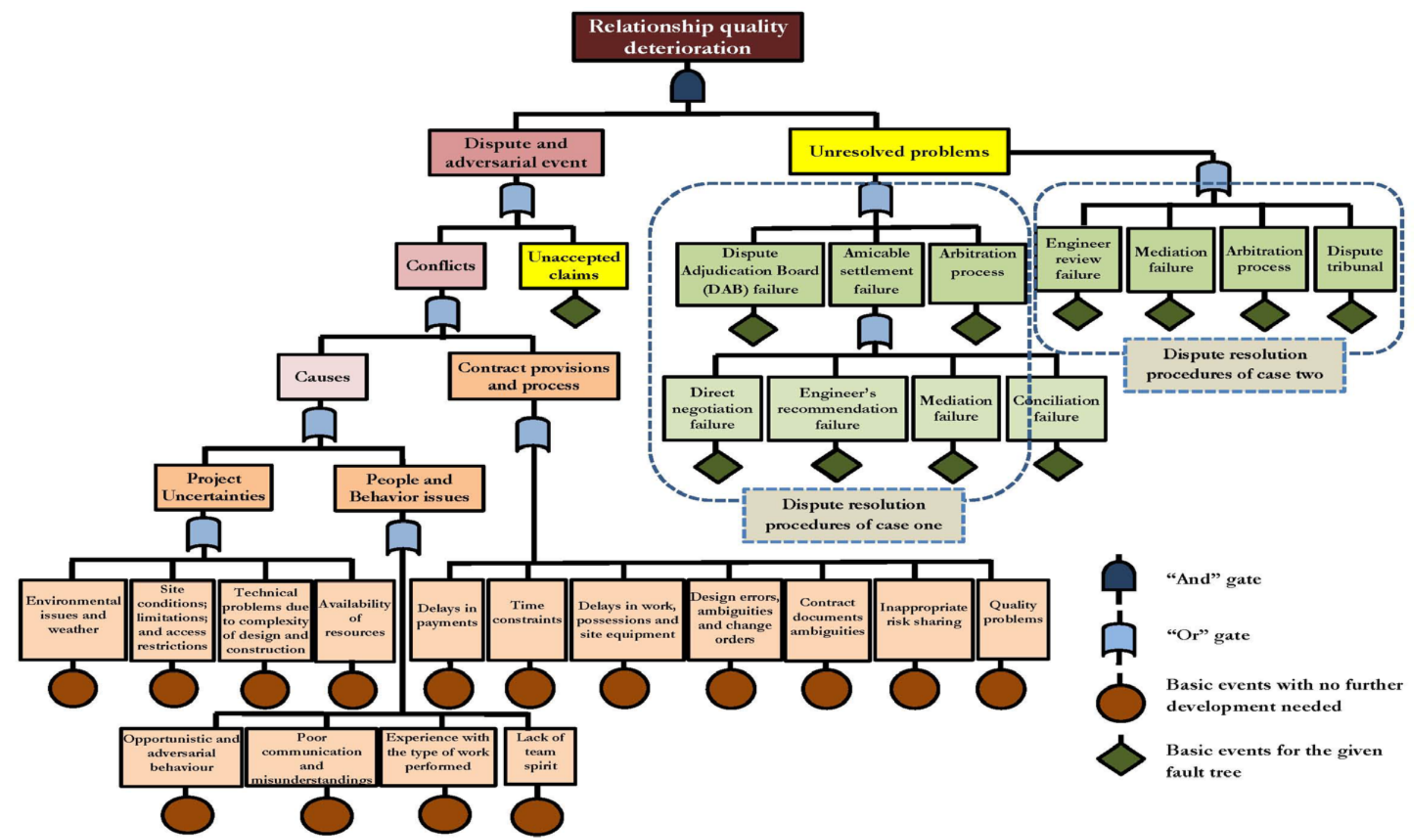

Figure 5: Fault Tree Analysis of the systematic framework of relationship quality 


\section{Conclusions}

Based on previous work and logical deduction, a systematic framework for relationship quality has been suggested. It was shown that the current systematic frame work is not a generalized structure which could fit all project types. The framework has been adjusted to fit the events occurring during a conflict/dispute incident which are distributed in consecutive layers. The probability for the occurrence of certain causes of conflict and dispute as part of the triggering layer will change due to the project type. It was also demonstrated that the conditions of contract can have a defining effect on the moderation layer of the systematic framework by identifying the procedures of conflict management and dispute resolution in their content. Consequently type of project, contracting arrangement and build environment culture determines the systematic framework of relationship quality for different projects.

Fault Tree Analysis of the identified system can show the possible combinations of components, causes and events which could lead to system failure and relationship deterioration. The probability of failure based on the occurrence of each event could also be calculated. The FTA can also be employed as a monitoring tool for relationship quality in different circumstances. The ability to have such indications about relationship quality may help increase performance alongside stirring sustainable procurement. The basic idea is to find out what possible circumstances and events may lead to relationship failure. The other issue is to make the best decision, either to take preventive or amendment actions to keep and maintain relationships, or to consider whether the relationship should be broken.

\section{Research Limitation}

In this study relationship quality is seen as a systematic cycle with components included in a conflict/dispute incident. Other components with potential influence on relationships have not been included in the scope and require further research. The article is a suggestion for future research in the domain of relationship quality; via the application of general systems theory and system reliability theory. The cases selected where used to identify how different contractual arrangements can influence the system failure model. However further data needs to be collected to empirically test the model.

\section{References}

Alderman, N. and Ivory, C., 2007. Partnering in major contracts: Paradox and metaphor. International Journal of Project Management, 25(4), pp.386-93. doi: http://dx.doi.org/10.1016/j.ijproman.2007.01.002.

Andrews, J.D. and Beeson, S., 2003. Birnbaum's measure of component importance for noncoherent systems. Reliability, IEEE Transactions on Reliability, 52(2), pp.213-19. doi: 10.1109/tr.2003.809656. doi: http://dx.doi.org/10.1109/TR.2003.809656

Barnett, R.S., 1997. Alternate dispute resolution: A growth industry. Building Design \& Construction, Mar 1997, 38(3), p.44.

Bennett, J., Peace, S. and Chartered Institute of Building, 2006. Partnering in the construction industry : code of practice for strategic collaborative working. Amsterdam [u.a.]: Elsevier Butterworth-Heinemann.

Blanchard, B.S. and Fabrycky, W.W.J., 2011. Systems Engineering and Analysis. USA: Pearson Education Limited.

Bristow, D.J. and Vasilopoulos, R., 1995. The new CCDC 2: facilitating dispute resolution of construction projects. Construction Law Journal, 11(2), pp.95-117.

Bygballe, L.E., Jahre, M. and Swärd, A., 2010. Partnering relationships in construction: A literature review. Journal of Purchasing and Supply Management, 16(4), pp.239-53. doi: http://dx.doi.org/10.1016/i.pursup.2010.08.002

Chan, A.P.C. and Chan, A.P.L., 2004. Key performance indicators for measuring construction success. Benchmarking: An International Journal, 11(2), pp.203-21. doi: 10.1108/14635770410532624. doi: http://dx.doi.org/10.1108/14635770410532624

Chaudhuri, A., 1997. Consumption Emotion and Perceived Risk: A Macro-Analytic Approach. Journal of Business Research, 39(2), pp.81-92. doi: 10.1016/s0148-2963(96)00144-0. doi: http://dx.doi.org/10.1016/S0148$\underline{2963(96) 00144-0}$ 
Chaudhuri, A., 1998. Product class effects on perceived risk: The role of emotion. International Journal of Research in Marketing, 15(2), pp.157-68. doi: 10.1016/s0167-8116(97)00039-6. doi: http://dx.doi.org/10.1016/S01678116(97)00039-6

Che Ibrahim, C.k.I., Costello, S.B. and Wilkinson, S., 2013. Development of a conceptual team integration performance index for alliance projects. Construction Management and Economics, 31(11), pp.1128-43. doi: 10.1080/01446193.2013.854399. doi: http://dx.doi.org/10.1080/01446193.2013.854399

Chen, W.T. and Chen, T.T., 2007. Critical success factors for construction partnering in Taiwan. International Journal of Project Management, 25(5), pp.475-84. doi: 10.1016/j.ijproman.2006.12.003. doi: http://dx.doi.org/10.1016/i.ijproman.2006.12.003

Cheung, S.O. and Yiu, T.W., 2006. Are Construction Disputes Inevitable? Engineering Management, IEEE Transactions on Reliability, 53(3), pp.456-70.

Construction Industry Review Committee, 2001. Construct for excellence, The Tang Report. The Government of the Hong Kong, SAR.

Cox, A. and Thompson, I., 1997. 'Fit for purpose' contractual relations: determining a theoretical framework for construction projects. European Journal of Purchasing \& Supply Management, 3(3), pp.127-35. doi: 10.1016/s09697012(97)00005-1. doi: http://dx.doi.org/10.1016/S0969-7012(97)00005-1

Crosby, L.A., Evans, K.R. and Cowles, D., 1990. Relationship Quality in Services Selling: An Interpersonal Influence Perspective. The Journal of Marketing, 54(3), pp.68-81. doi: http://dx.doi.org/10.2307/1251817

Egan, J., 1998. Rethinking Construction. London: Department of Trade and Industry.

Eriksson, P.E., Atkin, B. and Nilsson, T., 2009. Overcoming barriers to partnering through cooperative procurement procedures. Engineering, Construction and Architectural Management, 16(6), pp.598-611. doi: 10.1108/09699980911002593. doi: http://dx.doi.org/10.1108/09699980911002593

Gardiner, P.D. and Simmons, J.E.L., 1992. Analysis of conflict and change in construction projects. Construction Management and Economics, 10(6), pp.459-78. doi: http://dx.doi.org/10.1080/01446199200000046

Gualandris, J. and Kalchschmidt, M., 2014. Customer pressure and innovativeness: Their role in sustainable supply chain management. Journal of Purchasing and Supply Management, 20(2), pp.92-103. doi: http://dx.doi.org/10.1016/i.pursup.2014.03.001.

Hennig-Thurau, T. and Klee, A., 1997. The impact of customer satisfaction and relationship quality on customer retention: A critical reassessment and model development. Psychology and Marketing, 14(8), pp.737-64. doi: 10.1002/(sici)1520-6793(199712)14:8<737::aid-mar2>3.0.co;2-f. doi: http://dx.doi.org/10.1002/(SICI)15206793(199712)14:8<737::AID-MAR2>3.0.CO;2-F

Hitchins, D.K., 2007. Systems Engineering a 21st Century Systems Methodology. John Wiley

DOI: 10.1002/9780470518762. doi: http://dx.doi.org/10.1002/9780470518762

Høyland, A. and Rausand, M., 2009. System Reliability Theory: Models and Statistical Methods. John Wiley.

Jehn, K.A. and Mannix, E.A., 2001. The Dynamic Nature of Conflict: A Longitudinal Study of Intragroup Conflict and Group Performance. The Academy of Management Journal, 44(2), pp.238-51. doi: http://dx.doi.org/10.2307/3069453

Jelodar, M.B. and Yiu, T.W., 2012a. Evaluation of relationship quality in construction cases using a process model of conflict and disputes in project management. In: The 8th International Project Management Conference (IPMC2012), Tehran, Iran.

Jelodar, M.B. and Yiu, T.W., 2012b. Systematic framework of conflict, dispute and relationship quality in construction projects. In: 37th Annual Conference of the Australasian Universities Building Educators Association (AUBEA). Australia: The University of New South Wales.

Jelodar, M.B., Yiu, T.W. and Wilkinson, S., 2013a. In Search of Sustainability: Constructability Application and Contract Management in Malaysian Industrialized Building Systems. Journal of Legal Affairs and Dispute Resolution in Engineering and Construction, 5(4), pp.196-204. doi: 10.1061/(ASCE)LA.1943-4170.0000121. doi: http://dx.doi.org/10.1061/(ASCE)LA.1943-4170.0000121

Jelodar, M.B., Yiu, T.W. and Wilkinson, S., 2013b. Stirring sustainable procurement by conceptualizing relationship quality in construction. In: World Building Congress 2013. Brisbane Convention \& Exhibition Centre, Queensland, Australia.

Kast, F.E. and Rosenzweig, J.E., 1970. Organization and management: a systems approach. McGraw-Hill.

Kumaraswamy, M.M., Rahman, M.M., Ling, F.Y.Y. and Phng, S.T., 2005. Reconstructing Cultures for Relational Contracting, ASCE, p.131.

Lages, C., Lages, C.R. and Lages, L.F., 2005. The RELQUAL scale: a measure of relationship quality in export market ventures. Journal of Business Research, 58(8), pp.1040-48. doi: 10.1016/j.jbusres.2004.03.001. doi: http://dx.doi.org/10.1016/j.jbusres.2004.03.001

Latham, M., 1994. Constructing the team : Joint Review of Procurement and Contractual Arrangements in the United Kingdom Construction Industry : final report. London: H.M.S.O.

Ling, F.Y.Y. and Li, S., 2012. Using social network strategy to manage construction projects in China. International Journal of Project Management, 30(3), pp.398-406. doi: http://dx.doi.org/10.1016/j.ijproman.2011.05.010. 
Ling, F.Y.Y., Ong, S.Y., Ke, Y., Wang, S. and Zou, P., 2014. Drivers and barriers to adopting relational contracting practices in public projects: Comparative study of Beijing and Sydney. International Journal of Project Management, 32(2), pp.275-85. doi: http://dx.doi.org/10.1016/j.ijproman.2013.04.008.

Love, P.E.D., Irani, Z., Cheng, E. and Li, H., 2002. A model for supporting inter-organizational relations in the supply chain. Engineering Construction and Architectural Management, 9(1), pp.2-15. doi: http://dx.doi.org/10.1108/eb021202, http://dx.doi.org/10.1046/i.1365-232X.2002.00225.x

Meng, X., 2010. Assessment framework for construction supply chain relationships: Development and evaluation. International Journal of Project Management, 28(7), pp.695-707. doi: http://dx.doi.org/10.1016/j.ijproman.2009.12.006

Meng, X., 2012. The effect of relationship management on project performance in construction. International Journal of Project Management, 30(2), pp.188-98. doi: http://dx.doi.org/10.1016/j.ijproman.2011.04.002.

Pheng, L.S., 1999. The extension of construction partnering for relationship marketing. Marketing Intelligence \& Planning, 17(3), pp.155-62. doi: http://dx.doi.org/10.1108/02634509910271614

Pondy, L.R., 1967. Organizational Conflict: Concepts and Models. Administrative Science Quarterly, 12(2), pp.296-320. doi: http://dx.doi.org/10.2307/2391553

Rahman, M. and Kumaraswamy, M., 2004. Potential for Implementing Relational Contracting and Joint Risk Management. Journal of Management in Engineering, 20(4), pp.178-89. doi: 10.1061/(asce)0742597x(2004)20:4(178). doi: http://dx.doi.org/10.1061/(ASCE)0742-597X(2004)20:4(178)

Sako, M., 1992. Price, Quality and Trust: Inter-firm Relations in Britain and Japan: Cambridge University Press. doi: http://dx.doi.org/10.1017/СВ09780511520723

Totterdill, B.W., 2006. FIDIC User's Guide: A Practical Guide to the 1999 Red Book. Institute of Civil Engineers Publication. London: Thomas Telford Ltd.

Winch, G.M., 2000. Institutional reform in British construction: partnering and private finance. Building Research \& Information, 28(2), pp.141-55. doi: http://dx.doi.org/10.1080/096132100369046

Wolstenholme, A., 2009. Never W aste a Good Crisis: A Review of Progress since Rethinking Construction and Thoughts for Our Future. London SW1W 0PP: Constructing Excellence, Warwick House, 25 Buckingham Palace Road

Yeung, J.F.Y., Chan, A.P.C. and Chan, D.W.M., 2012. Defining relational contracting from the Wittgenstein familyresemblance philosophy. International Journal of Project Management, 30(2), pp.225-39. doi: http://dx.doi.org/10.1016/j.iproman.2011.06.002.

Yeung, J.F.Y., Chan, A.P.C., Chan, D.W.M. and Li, L.K., 2007. Development of a partnering performance index (PPI) for construction projects in Hong Kong: a Delphi study. Construction Management and Economics, 25(12), pp.1219-37. doi: 10.1080/01446190701598673. doi: http://dx.doi.org/10.1080/01446190701598673

Zou, W., Kumaraswamy, M., Chung, J. and Wong, J., 2014. Identifying the critical success factors for relationship management in PPP projects. International Journal of Project Management, 32(2), pp.265-74. doi: http://dx.doi.org/10.1016/j.ijproman.2013.05.004. 